\title{
Review Article \\ Integrating Contemplative Tools into Biomedical Science Education and Research Training Programs
}

\author{
Rodney R. Dietert \\ Department of Microbiology and Immunology, College of Veterinary Medicine, Cornell University, North Tower Road, \\ Ithaca, NY 14853, USA \\ Correspondence should be addressed to Rodney R. Dietert; rrd1@cornell.edu
}

Received 15 February 2014; Accepted 21 May 2014; Published 2 July 2014

Academic Editor: Geoffrey Lighthall

Copyright (C) 2014 Rodney R. Dietert. This is an open access article distributed under the Creative Commons Attribution License, which permits unrestricted use, distribution, and reproduction in any medium, provided the original work is properly cited.

Academic preparation of science researchers and/or human or veterinary medicine clinicians through the science, technology, engineering, and mathematics (STEM) curriculum has usually focused on the students (1) acquiring increased disciplinary expertise, (2) learning needed methodologies and protocols, and (3) expanding their capacity for intense, persistent focus. Such educational training is effective until roadblocks or problems arise via this highly-learned approach. Then, the health science trainee may have few tools available for effective problem solving. Training to achieve flexibility, adaptability, and broadened perspectives using contemplative practices has been rare among biomedical education programs. To address this gap, a Cornell Universitybased program involving formal biomedical science coursework, and health science workshops has been developed to offer science students, researchers and health professionals a broader array of personal, contemplation-based, problem-solving tools. This STEM educational initiative includes first-person exercises designed to broaden perceptional awareness, decrease emotional drama, and mobilize whole-body strategies for creative problem solving. Self-calibration and journaling are used for students to evaluate the personal utility of each exercise. The educational goals are to increase student self-awareness and self-regulation and to provide trainees with value-added tools for career-long problem solving. Basic elements of this educational initiative are discussed using the framework of the Tree of Contemplative Practices.

\section{Introduction}

Recently in developing a university course to prepare students for a lifelong career in research, an opportunity arose to consider the conflicting duality that exists in science, technology, engineering, and mathematics (STEM) based preparation of a well-educated, fully-prepared research scientist. This conflicting duality is discussed by R. R. Dietert and J. Dietert [1]. For example, if one were to characterize well-trained scientists and health research professionals, the descriptive phrases would likely include focused experts in a significant disciplinary area (subspecialty), rigorously steeped in the scientific method, engaged in critical thinking and doggedly pursuing hypotheses, embarked on an incremental path to gain scientific/medical recognition and credibility, and synched with current funding/medical support. But there are other phrases that are equally useful in describing researchers who have achieved the most significant breakthroughs in scientific discovery. Those descriptors are more likely to include such phrases as follows: are flexible and adaptable, can move into new areas and help to define new research arenas, will readily discard outdated paradigms, will forge new thinking by swimming against the predominate scientific current when necessary, and are visionaries whose work will become recognized as important in the future [1].

Both of these seemingly-opposed aspects are accurate and will be needed among tomorrow's well-trained, most creative researchers. Across a scientific career, doggedly embracing existing paradigms can be useful at times just as sweeping aside the same paradigm and even the surrounding dogma may be critical for real progress later. The limitation with recent academic curriculum in the sciences is that our current training programs are remarkably effective in helping students embrace the first set of descriptors. But these programs have had little to offer in helping to instill flexibility, adaptability, and first-person-based discernment among students on the research and health professional paths. Part of the solution to this current training gap may 
reside in bringing contemplative education formally into the university STEM curriculum.

During the past 5-10 years there has been an active effort to bring contemplative practices into the curricula of higher education. Among the benefits is that such instruction affords the students with first-person learning that has generally been lacking in the third-person driven, heavily didactic academic programs. Contemplative practices include a wide array of apparently quite distinct activities that have been organized into a tree of contemplative practices as shown in Figure 1 $[2,3]$. The "Tree" template of contemplative practices has as its roots communion, connection, and self-awareness as supported by seven major branches of activities/states (creation, movement, stillness, activist, generative, ritualistic/cyclical, and relational). It serves as a useful pedagogical foundation for the design, incorporation, and pursuit of activities that can aid the student in both the immediate academic endeavors as well as the longer-term life's goals.

Institutions such as the University of Massachusetts at Amherst, Brown, Vanderbilt, Rice, Emory, University of California-San Diego, and the University of Virginia have made significant strides in offering contemplative curricula to students. The majority of these offerings have been focused outside of the sciences (e.g., religion courses) [4] with others emerging from psychology curriculum offerings such as the recent Contemplative Studies Project at New York University (http://postdocpsychoanalytic.as.nyu.edu/page/contemplative.studies). However, there is considerable interest in expanding this curriculum to STEM and, particularly, the health sciences and biomedical research training programs [5].

There is a considerable effort underway concerning best practices within STEM education to help produce much needed future generations of scientists. This initiative includes the commitment of a variety of organizations ranging from the National Governor's Association [6] to the National Research Council [7] and the STEM Education Coalition [8]. With this initiative comes a window of opportunity to help design both a K-12 and higher educational curriculum that supports the development of highly-intuitive scientists. This paper details the experience of introducing a contemplative education-based course into a portion of the STEM curriculum, undergraduate biomedical sciences, at Cornell University. The course materials and associated textbook Science Sifting: Tools for Innovation in Science and Technology [1] arose as a result of personal contemplative training and experiences that produced (1) a series of concept papers [9-11], (2) material connected to an in-production documentary film (MicroBirth, AltoFilms), and (3) encouragement from colleagues to teach whatever it was that I was doing in my own science career.

\section{Contemplative Practices in the Biomedical Sciences}

In 2012, a new initiative was undertaken at Cornell University to introduce contemplative practices into the biomedical science curriculum. The double-listed course, Animal Science (ANSC) and Biomedical Science (BIOMS) 4400 Tools for a
Lifelong Career in Research, is designed to prepare students for a biomedically oriented career including research. A majority of students from the course are planning to pursue pos-baccalaureate degrees (MD, DVM, Ph.D., or combined degree programs). As a result, the course supports not only students pursuing biomedical research careers, but also those entering the professions of human and veterinary medicine.

Materials from BIOMS 4400 have been offered beyond the course via workshops for medical schools, veterinary medicine programs, and scientific societies. Among these are workshops for (1) graduate students and postdoctoral trainees at a multidepartment Cornell health science research retreat, (2) the National Institute of Environmental Health Sciences- (NIEH-) supported Environmental Health Sciences Center at the Harvard School of Public Health, (3) the Annual Leadership Conference for the East Carolina Medical School (where continuing medical education credit was offered), (4) the Cornell Veterinary Business Management Certificate Program, and (5) a Postdoctoral Assembly-sponsored event at the annual meeting of the Society of Toxicology.

\section{Vantage Points}

The ultimate goal of the contemplative exercises and material contained in ANSC/BIOMS4400 is to enable the student to gain multiple vantage points (i.e., multiple viewing positions) surrounding any informational pattern. The concept of vantage points has been likened to occupying multiple seats in a baseball stadium almost simultaneously. It is difficult to have the best view of a given play in the field from only one seat. But if you could occupy multiple seats almost simultaneously, then you have more views and are more likely to have a useful view of almost any play. This is depicted visually in Figure 2. The individual has multiple vantage points and can access multiple views as a play unfolds on the field. There is less chance to miss seeing a play as a useful vantage point is readily available. For creative problem solving, there are reasons why it is desirable to have more vantage points and, as a result, access to more information surrounding a roadblock or problem. In his recent analysis of real-life problem solving, McCaffrey [12] concludes that a key to innovative, research-driven problem solving is the capacity to notice obscure features not seen by others. This is central to the tenet of the BIOMS 4400 educational effort that by providing budding scientists with tools for more vantage points during problem solving, the greater the chance they will see something resulting in a solution.

Not all course materials designed to increase vantage points fall clearly within the contemplative practice model. For example, during the class students are asked to become neutral observers by actively taking on the role of an alien visitor from another planet (using an exercise called The Alien Observer Exercise). They engage in play-related activity to take on the openness of a five-year old. They learn to progress in their work even as they sleep using techniques such as task reactivation [13], to choose their words wisely, and to actively use their bodies to draw upon embodied cognition. They learn to effectively jump between their 


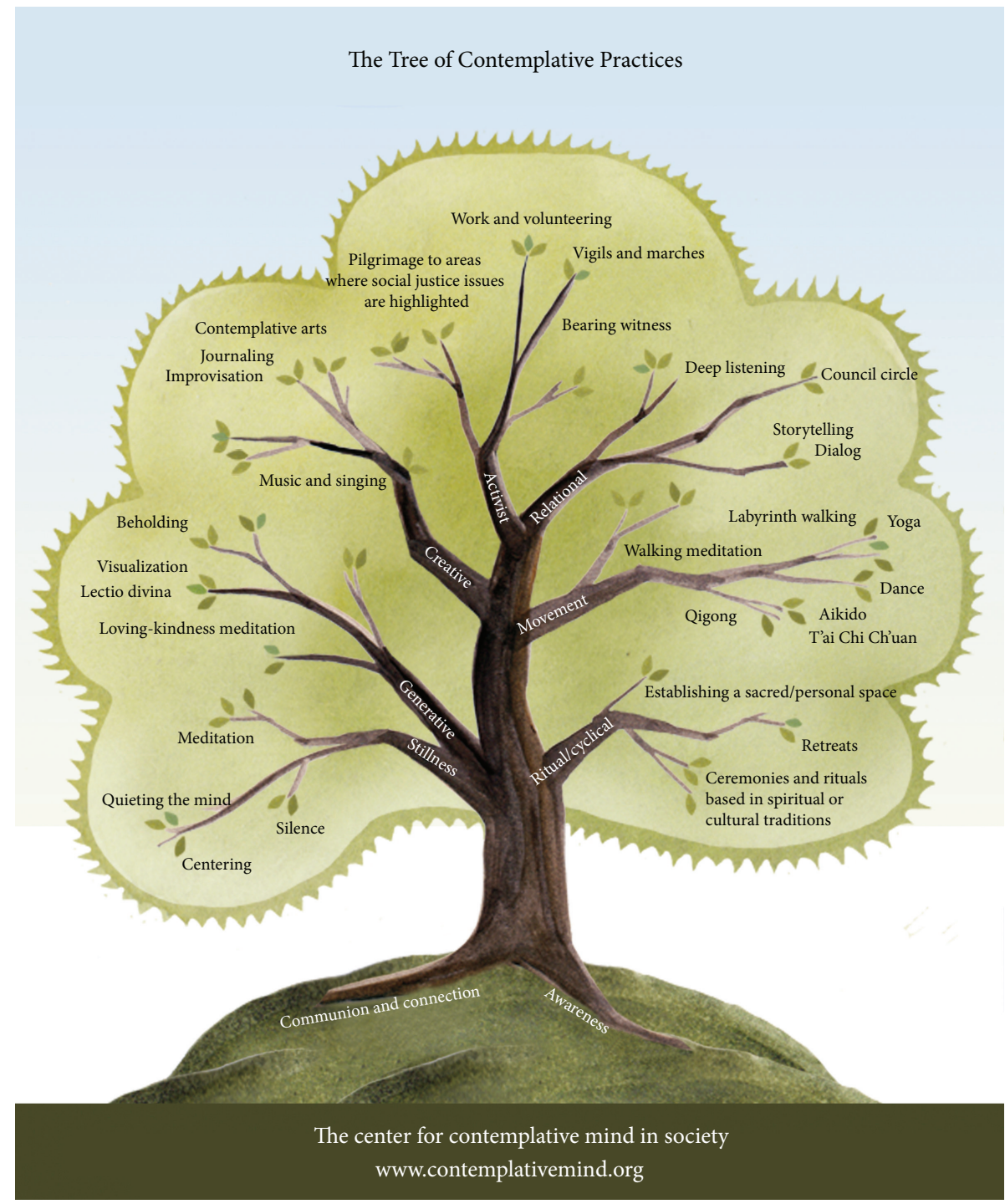

Figure 1: The Tree of Contemplative Practices (reproduced with permission of The Center for Contemplative Mind in Society http://www.contemplativemind.org/). Practices illustrated in the branches help nurture increased self-awareness and access to information.

hobbies and scientific work such that progress on one can feed advancement in the other. However, the act of contemplation lies at the core of gaining more vantage points as the observer. When students realize that the simple act of meditation can shift their entire perception of fundamental information, they realize how much of their world they have not perceived.

\section{Self-Awareness and Self-Regulation Training}

Courses that teach thinking-outside-the-box strategies are not novel to universities including medical schools and have become an important part of the academic landscape [14]. The emergence of this curriculum is quite useful. However, these courses often emphasize analytical approaches to generate novel thinking rather than to present students with a distinctly different compass for navigating the world. One of the benefits of the incorporation of contemplative practices into the STEM curriculum is that it allows students to broaden their strategies for gathering information. Additionally, they can develop two skills that will serve them well later in life: to increase their personal self-awareness (the layers of personal identity gleaned through consciousness) and their capacity for self-regulation [15-17]. Here the term self-regulation is used to mean the ability to focus one's awareness differently at will. The latter allows students to slip seamlessly between different states of perceptional awareness and differences in focus. For example, they can have the opportunity to compare their views of a problem from the differing perspective of (1) a highly analytical, typical scientific focus, (2) a heart-centered meditative perspective, and (3) a role-playing alien life form's neutral observations. The information they get from these three different views is simply not the same.

Through contemplative practices, students can discover aspects of self that have either been hidden away or rarely 

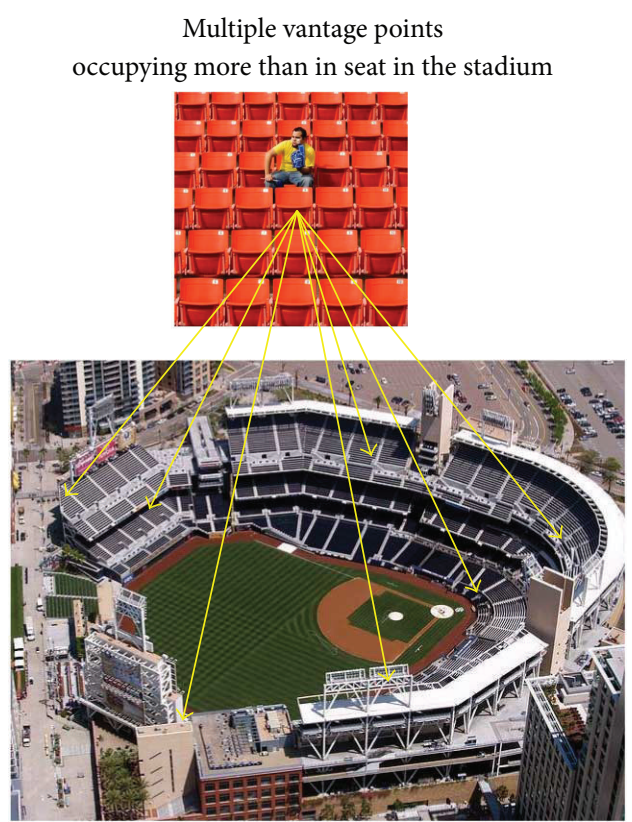

Figure 2: Contemplative practices allow the observer to gain multiple vantage points. For the biomedical scientist, this is akin to having more available data and impressions surrounding any issue. It has been likened to a person being able to occupy multiple seats in a baseball stadium simultaneously, thereby having a better view of an otherwise partially obstructed play [1]

visited. It is not uncommon to have students make comments in their journals or following in-class exercises such as I never realized that about myself, I was not aware how important that is for me, I now know that this is when I am the happiest. In fact, the experiences derived from using the contemplative tools discussed in the following sections can be quite profound. Based on comments from the course evaluations and student journals, students may (for the first time) connect with their inner core (i.e., personal awareness of life's purpose) and self-identify the work, interests, and activities that, for them, support a joyful life. The transformative aspect of student experience can be personally powerful and revealing. For example, in 2013 it resulted in a student-initiated nomination leading to a teaching award connected to the Cornell 4400 course.

According to the present theoretical framework, increased self-awareness and a more holistic, full-body consciousness allows students to move seamlessly between the traditional analytical mode of scientific investigation and the more broadly perceptive and personally-intuitive view that can come from the application of contemplative practices. Prominent examples of such applications are a rich part of the Cornell's history, and the students in BIOMS 4400 are led through those examples during the first class session. Whether it is Richard Feynman watching students engaged in play in a Cornell cafeteria [18], or the former improvisational jazz banjo player [19], Barbara McClintock, gazing from a Cornell hillside over her maize plants and having an intuitive knowing about her plants [20], the insights are there for the taking for students who are prepared to observe things differently. Stories of the discoveries of Richard Feynman, Barbara McClintock, and others form part of the introduction to both the Cornell course and textbook [1]. Additionally, they have been used at other institutions (e.g., Professor Arthur Zajonc at Amherst College) as part of a more transformative and reflective pedagogy [21]. It is the well-trained and self-aware student who is ready to access the Feynman- and McClintock-type insights.

\section{Tree of Contemplative Practices as Used in ANSC/BIOMS 4400 and Health Professional Workshops}

Application of the contemplative practices in the classroom as shown in the Tree of Contemplative Practices (Figure 1) and Table 1 can have multiple potential benefits including reduction in stress [22-24]. However, it is one benefit above the others that drives the inclusion of contemplative practices in BIOMS 4400 and the workshops: the opportunity for students and trainees to shift their focus and perspective and gain additional vantage points surrounding problems. The additional vantage points, in turn, allow access to more information.

The following sections describe parallels between materials and exercises in the Cornell course, workshop, and textbook and specific components of the Tree of Contemplative Practices. This discussion of relatedness between course-associated materials and the Tree is organized by the relevant Tree branch groupings (Stillness, Generative, Creative, Activist, Relational, Movement, Ritual/Cyclic) as seen in Figure 1.

\subsection{Stillness}

5.1.1. Meditation. Meditation involving guided focus has been reported to affect a variety of physiological $[25,26]$, psychological [27] and experiential [28] outcomes, though the progress toward outcomes is often nonlinear [29]. Among those most recently described by Lindah et al. [30] is a phenomenon of light-form experiences that are similar to those seen during periods of sensory deprivation and increased neuroplasticity.

In the one-credit hour Cornell course and workshops, the stated goal is to enable biomedical students and research scientists to learn contemplative-based tools for overcoming roadblocks. All of the tools are designed to enable students to see the roadblocks differently by changing themselves as the observer. The tools, including meditation, allow the science students to increase their vantage points (i.e., viewing positions) surrounding a roadblock or problem. As depicted in Figure 2, the student using meditation to view a problem is gaining an additional vantage point equivalent to shifting to another seat in the baseball stadium. An emphasis is placed on being able to shift vantage points quickly, thereby, getting multiple views of a problem almost simultaneously. A priority was given for easily-taught, rapid meditation processes so that students have the opportunity to record their different views 
TABle 1: Cornell materials and exercises aligned with the Tree of Contemplative Practices*.

\begin{tabular}{|c|c|c|}
\hline $\begin{array}{l}\text { Contemplative practices } \\
\text { (branch-practice) }\end{array}$ & Exercises and/or course materials & $\begin{array}{l}\text { Science Sifting (textbook) section or other } \\
\text { materials** }\end{array}$ \\
\hline Stillness-Meditation & $\begin{array}{l}\text { The } 30 \text {-Second Meditation Exercise; The Meditation on } \\
\text { the Road Exercise }\end{array}$ & Chapter 15 pp. $186-187 ; 190$ \\
\hline Stillness-Quieting the Mind & $\begin{array}{l}\text { The Wall of Information Exercise } \\
\text { The Alien Observer Exercise }\end{array}$ & $\begin{array}{l}\text { Class/Workshop Materials } \\
\text { Chapter } 16 \text { p. } 195\end{array}$ \\
\hline Stillness-Centering & The Body as a Weathervane Exercise & Chapter 8 p. 94 \\
\hline Generative-Visualization & Focusing on the End Target & Chapter 3 pp. $92-93$ \\
\hline Generative-Beholding & The Art is Information Exercise & Chapter 18 pp. $230-231$ \\
\hline Creative-Music and Singing & The Music Appreciation Exercise & Chapter 18 p. 217 \\
\hline Creative-Contemplative Arts & The Remodeling Exercise & Class/Workshop Materials \\
\hline Creative-Improvisation & The Mime in the Box Exercise & Chapter 28 p. 226 \\
\hline Creative-Journaling & $\begin{array}{l}\text { Journaling of Class Exercises } \\
\text { The Feed the Journal Exercise }\end{array}$ & Chapter 13 p. 162 \\
\hline Relational-Storytelling & $\begin{array}{l}\text { The Writing Your Story Backwards and Forwards } \\
\text { Exercise }\end{array}$ & Chapter 3 p. 41 \\
\hline Movement-Dance & $\begin{array}{l}\text { The Walk Around Exercise; Choreographing Your } \\
\text { Experiments; Dancing Your Ph.D. }\end{array}$ & Chapter 10 p. 119 ; Chapter 18 pp. $222-225$ \\
\hline Ritual-Cyclical-Personal Space & The Office Space Exercise & Chapter 9 p. 113 \\
\hline
\end{tabular}

repeatedly across different exercises during the relatively brief, one-credit hour course.

Additionally, one rationale was that easily-performed, brief meditations producing tangibly useful results would be more likely to be adopted and practiced by STEM students. For this purpose, a 30-second, heart-focused, guided meditation is employed repeatedly during the course. In several exercises, students personally record what they notice when viewing a given target as they compare the information that is available to them from a nonmeditative and then from a meditative state. In the initial training, a painting by Salvatore Dali is used for students to record what they notice about the painting both before and then during meditation (described in more detail in the Beholding section). It is at this point that students realize they have additional information available to them for use in decision making when they include the vantage point provided by meditation. Quick access to a meditative state allows them to frequently compare (nonmeditative versus meditative) information as problems/challenges arise during the semester.

Four exercises are employed including meditation: the introductory 30-Second Meditation Exercise, The Remodeling Exercise, which combines meditation with use of embodied cognition, representational symbology, and play, The Wall of Information Exercise (described in the next section), and The Taking Heartspace-Based Meditation on the Road Exercise. The last exercise invites students, postdoctoral trainees, and senior scientists to pursue a traditional science-driven activity (e.g., attending a session of one's national scientific conference and deciding which sessions to attend) by using a nonconventional method of selection. In this case, the students use cues obtained via meditation to select the presentations to attend in contrast to the well-worn conventional methods for identifying those presentations most closely related to one's disciplinary research area. They are operating based on what they noticed and not on what is logical based on some prescribed rule set. The exercise is one of trusting an internal navigation that produces a different conference schedule than a herd-mentality-designated agenda. This enables students to gauge their personal boundaries of trust for contemplative, internally-derived information.

5.1.2. Quieting the Mind. Quieting the mind can be a very helpful, value-added tool for the scientist and health practitioner as it allows for a different method of both gathering and examining information. The focus of the quiet mind state is different from that usually found during traditional attempts to analytically work through a stubborn problem. For the sake of this discussion, the latter will be termed "the noisy mind." That is the traditional tendency to further increase one's focus on a stubborn problem or roadblock diving deeper and deeper into the problem's details in search of an elusive solution. The more stubborn the problem is, the more frustration and emotions may increase. In fact, a noisy mind state is ripe for emotions and drama where anxiety can become increasingly intertwined with observations [31]. Neutrality of observation is an important aspect of the quiet mind state as discussed by Rinpoche and Swanson [31]. If drama and emotions do surface, they are viewed from a neutral observer state. Teaching students how to set aside or step outside of drama in making observations is an important goal of the course.

Three exercises from the Cornell BIOMS 4400 course help students to quiet the mind and allow them to gather and examine information differently: (1) the previouslymentioned Alien Observer Exercise where students role-play 
the part of an alien observer walking among humans, (2) a drama-connected exercise where students use music to quiet the mind, and (3) an exercise called The Wall of Information. With these exercises students learn to step outside of the drama and emotions that can easily fill our electronically wired, news-laden lives. They have the opportunity to directly compare the information they get from both the noisy-mind and quiet mind states.

With The Alien Observer Exercise, students are encouraged to take an interval (e.g., usually between 30 minutestwo hours as is possible) during a normal day and role-play the part of being a visitor from another planet. The planet's very survival is dependent upon the keen, unbiased, neutral observations of human activities by this alien observer. In this exercise because the alien has never before encountered humans, a quieted mind is essential. There are to be no prior assumptions, implied motives, or unnoticed actions. There are just observations and information. It is a useful tool for practicing how to see routine activities differently with a quieted mind.

With the drama-connected music exercise, students first read one or more tragic news stories of the day to heighten drama and emotions (a noisy-mind state). They then read a scientific abstract noting their comprehension and insights surrounding it. Then they play their favorite music or music videos until the drama and anxiety surrounding the news story have subsided. Again they read the same scientific abstract comparing the comprehension and insights available after the anxiety-reducing music therapy. From this exercise, students can personally calibrate the additional information that is available to them after setting aside drama and quieting the mind.

The third mind quieting exercise is one of the most profound exercises incorporated into the Cornell BIOMS 4400 course curriculum as well as the extended version of the workshop and involves a nonconventional method of tapping information by the health science students and workshop attendees. The Wall of Information Exercise is only conducted after the students have had several other classroom and take-home opportunities to use and calibrate broadened perceptional awareness via meditation-based exercises.

Instead of accessing information from the Internet, a journal article, or a book, the students are instructed to get information from the classroom wall. From a quiet-mind, meditative state, the students search for and locate a section of classroom wall that draws their attention. Connected with the wall, and from a place of deep stillness, they access available information.

They are, in effect, listening for information whether internal or external that is available to them as a result of noticing something different with the wall and allowing themselves to be sufficiently quieted in the mind and fully present to both trust and follow the noticed difference. The information, which may show up as concepts, snapshot images, colors, or sounds, is highly personalized. Sometimes the students have clear ideas as to the relationships surrounding the information; in other cases, it appears to lack obvious connection at that moment.
The experience of trusting that a novel idea or image can emerge from something that otherwise might defy their traditional training (i.e., connection with a classroom wall) helps to build the students' confidence that work progress may be as near as the closest wall, or table or desk or even air space. It entrains the science students to expect potentially useful information to emerge anywhere and everywhere.

\subsection{Generative}

5.2.1. Beholding. Beholding is a tool often used with visual arts to gain a different perspective following a prolonged or second look [32]. An example of a beholding exercise for science students is that provided by Professor Michelle Francl in her physical chemistry course at Bryn Mawr College. As described in Barbezat and Bush [33], Professor Francl introduces solutions to the Schrodinger equation by having students examine a data figure mindfully. Students write down their observations and these observations drive the subsequent discussion (as opposed to a predetermined, instructor-driven discussion.). There is an element of spontaneity and reliance on what shows up in that class among that specific group of students in the moment. It requires a different type of teaching.

Beholding exercises appear in both the Cornell course and the narrative textbook material. For the in-class exercise, students are asked to examine the image of a painting by Salvador Dali (Swans Reflecting Elephants, 1937) and to immediately write down the first 3-4 things they notice. They are asked to perform a brief guided meditation aided by the visual of a cute puppy. They are then presented with the same Dali painting and asked to write down the 3-4 things they notice. Invariably, the second set of cues discerned from the painting while in a brief meditative state bear little to no resemblance to those first noticed by each student. The students gain additional information not previously available to them. For a scientist, this is immediately recognizable as a significant asset. New perspectives gained via beholding involving lab data, hypotheses, paradigms, experimental protocols, symptoms and diagnoses, and therapeutics are likely to lead to more highly-informed decisions.

Haynes [32] at the University of Colorado has used the beholding of art face-to-face as a means of gaining additional insights previously unavailable with a brief passby. As described in Science Sifting [1], I have used a similar technique in the US National Portrait Gallery first visiting a work of art with the pass-by then immediately returning and asking an opened-ended question such as "Is there any information here for me?"

It is remarkable what information comes into the awareness via this type of beholding or contemplative inquiry. For example, specific elements within the painting may immediately and vividly stand out as if they were 3 -dimensional (3-D) holograms. These usually have a special meaning for the viewer. Alternatively, ideas or concepts come to the forefront. It may or may not be obvious how these are connected to the specific painting or artist. Some paintings may lack 
information for beholding for a given person at a particular viewing. The students in the Cornell course are encouraged to try this highly-personal exercise.

5.2.2. Contemplative Arts. Preparation of an art object associated with contemplative practices is known as contemplative art. One of the exercises used in the Cornell course and in extended versions of the workshops (but not included in the textbook) is called "The Remodeling Exercise." It involves aspects of contemplative art, symbology, and embodied cognition. For the exercise, each student selects a construction material with which to build a 3D object. Modeling clay and various forms of construction bricks and logs are among the options. The students construct a representation of a personal roadblock or problem. After drawing or photographing it, they then disassemble the model, enter a meditative state, and remodel a 3-D solution set constructed using the same materials. This is also documented. The students have physically worked on their roadblocks using information derived from the contemplative practice. They have produced a contemplative practice-derived work of art, although it may not be immediately recognizable as such in the traditional sense. Student feedback suggests that their connection to the perceived roadblock is completely different after physically remodeling the problem.

5.2.3. Visualization. Visualization is a key component in many of life's aspirations. Athletes can effectively use visualization to improve their performance and experiments suggest that visualized muscle training is not that different in outcome from actual gym-based muscle training [34, 35]. Similarly, a first-person-view passive observation of exercise appears to produce physiologically relevant responses in the observer that are associated with active exercise [36]. It begs the question of whether your body makes major distinctions between an intensely and holistically envisioned experience versus an actual experience?

Visualization is a key component to the student perceptions of a lifelong career in scientific research and/or health professions. Early in the course and workshops students are provided with an opportunity to envision themselves in the career roles they state they want for themselves. This is a simple but deep act of the students imagining themselves as health science professionals. They are asked to locate this envisioning within their body and evaluate when personal joy is connected with it. The exercise can allow students to bypass programmed assumptions about a future health science career (e.g., parental pressure/expectations). They are likely to have one of three types of outcomes from this experience. (1) Students are able to envision a clear movielike view of themselves in a health science career that is filled with joy. (2) Students do not get a clear view. Here, they are advised to be patient and try again later in the course. (3) Students may see themselves operating in the stated career but find it feels internally hollow and lacking joy. Here, they are quizzed about the activities that bring them joy and asked to begin envisioning a series of modified careers for comparison with their initial visualization. This exercise has supported some students in a reconsideration of their ultimate career goals even within different options for health science professions.

A second aspect of visualization is the opportunity to place a focus on the target rather than the path. This is exceptionally important. As described in Whitecloud's The Magician's Way [37], the more we focus on the minutia in the mechanics of a path or process, the less we connect with the end goal. If the end goal is where we envision ourselves, do we really need to micromanage the path? While the course offers details of processes toward advanced degrees in healthrelated sciences, we challenge students to keep their focus on the target and not to limit their options for getting there.

\subsection{Creative}

5.3.1. Journaling. As described by Barbezat and Bush [33] journaling is an ancient form of personal expression and exploration. Personal contemplative documentation has been a part of life evaluation and assessment for some time [38]. As a contemplative practice in academia, journaling can take several different forms. But one consistency is that journaling on a regular basis is encouraged. The academic entries can represent a simple documentation of events or activities or, alternatively, be a highly personalized reflective description of the emotions, mental, and physical attributes surrounding a day or activity [33].

Journaling has been used with two distinct goals in mind in BIOMS 4400. First, students are asked to keep a journal of all major in-class and take-home exercises. Here, the goal is to capture their calibration/results of the outcomes of these exercises. A personal, contemporary telling of the events is useful because the exercises often produce results that, early on, may be disbelieving for the student. A rereading of the personal journal re-enforces the experience.

A second type of journaling pertains to a class synchronicity exercise. Each day the students are asked to attempt to write about a synchronous event. It can be a synchronous event they have recalled from earlier in their life or one that has occurred the same day. Even if they are unable to recall an event for a given day, they are asked to briefly sit with the journal at hand in anticipation of an entry each day. As the exercise progresses across several weeks, the students find that the number of synchronous events they are entering in their journals increases dramatically. The act of the group exercise appears to produce more and more journaling activity.

5.3.2. Music. Music plays an important role in the Cornell course and textbook. Among the topics considered is the capacity of music to affect behavior at both the individual and group levels [39]. The history of and hypotheses concerning the use of different Hertz $(\mathrm{Hz})$ tuning for producing music (e.g., tuning to $A=432 \mathrm{~Hz}$ versus $A=440 \mathrm{~Hz}$ ) are also discussed. One of the exercises presented in the textbook is called The Music Appreciation Exercise. Students are asked to use music as a foundation for envisioning different multimedia realities: for example, different lyrics or music video action set to the same music or different artists performing 
the same song. The exercise is one of creativity in which permutations and movable parts of envisioning result in truly novel, previously unenvisioned, musical performances. Music-driven insight and scientific problem solving can become more seamlessly integrated following the example of Albert Einstein who worked on his physics while playing Mozart or Bach on the violin [1].

5.3.3. Improvisation. Improvisation and what Martha Beck terms "Deep Play" [40] are powerful tools to move deep into a wide-open inner child state and beyond limiting conventional wisdom. The body does not distinguish the work done in removing barriers during improvised role playing from those done through other means. With improvisation, if a student performs the act, it happened. Improvisation exercises have been used to facilitate science communication at the highest levels as evidenced by The US National Institutes of Health programming internal agency guided improvisational exercises led by Alan Alda [41]. SUNY-Stonybrook has created The Alan Alda Center for Communicating Science that teaches scientists tools such as improvisation (http://www.centerforcommunicatingscience.org/improvisation-for-scientists/).

Used during the course and also described via the textbook, The Mime in the Box Exercise is a guided meditation involving both movement and acted improvisation that allows students to identify and then shatter limiting barriers that they experience as surrounding themselves. The acted physical destruction of the limitations becomes a part of their body memory.

\subsection{Relational}

5.4.1. Storytelling. One of the most revealing participatory exercises for students interested in pursuing a health science career is one involving storytelling. Stories can help the individual to navigate the informational patterns that are presented during life. In particular, the stories we tell ourselves can either be freeing or constricting. In the Cornell contemplative science course, storytelling is used to shatter the major barrier in achieving a fulfilling career: the idea that there is only one path to a visualized end result of scientific academic training. The roadmap students have established for themselves by the time they enroll in our course is usually rigid and highly prescribed with little room for a perceived mis-step. This single-minded story is unwound when the students perform an exercise to write their stories backward and then forwards. This is adapted from the concepts of Martha Beck [42]. Following a formula, the students are asked to insert a then-perceived negative event that was key to their path to Cornell and our course. Few students had previously considered that without the "negative event," they would not be at Cornell and poised to jump to the next scientific career level. Recognizing that the perceived negative event led to a highly desirable academic position at Cornell shifts their value judgment not only of the past events but also as pertaining to current event. They become more neutral and more likely to take a wait-and-see attitude.
When the students then write their story forward projecting toward later life, they envision several distinctly different paths that nevertheless lead to a welcomed outcome. This increases their flexibility and adaptability in adjusting to what previously might have appeared to be severe roadblocks.

A second form of storytelling examined in the class is that of language usage. By the use of specific words and phrases, students tell themselves a story. That story can be open, expansive and, uplifting or confining, deflating, and restrictive. Often the words tell of personal limitations. Students can literally box themselves in by using confining language. In the Cornell course, two language-based tools are the use of metaphors to enhance creativity [43] and the use of mixed metaphors (e.g., take a flying hike) as a type of reset button for limiting thinking. Hitting the reset removes the limiting language template and allows the students a momentary clean slate of possibilities.

\subsection{Movement}

5.5.1. Dance. Contemplative dance provides an opportunity to increase self-awareness and to access and work with patterns of information within one's own body. It is sometimes called authentic dance [44]. One of the variations of guided dancing is known as ideokinesis [45], which is used to release unhelpful patterns in the body.

Within the Cornell course, students are exposed to three examples of dancing for information. The first is an example called "Dance Your Experiment" [46] detailing scientific experimental design as analyzed via dance choreography. A second example is the program established by Science Magazine called "Dance your Ph.D." [47]. Since its initiation in 2008, the program has become so successful that submissions are now divided into several different fields of study for the competition. According to Myers [48], "Dance Your Ph.D." involves body work combined with affective entanglements. Myers concludes that the "enthusiasm with which scientists have embraced the Dance Your PhD contests suggests that they are on the look-out for ways to resist discursive conventions that limit what is possible for them to see, to say, to imagine and to feel." [48, page 178].

The final course example involves movement (more than a prescribed dance) and the idea that information is really three-dimensional (3D) in nature and, as result, is best viewed from all sides. In The Walk-Around Exercise, students are asked to notice their impressions of an asymmetrical, 3D object as they move their bodies around the perimeter of the object. The act of physically moving to different vantage points creates two apparent outcomes: (1) students see more than anticipated based on a front-only view and (2) students see things that are not predicted based on the nature of the object. Interestingly, across the multiple course offerings and workshops there has been a tendency for students to report seeing the same anomalies (e.g.,sharks on a statue clearly containing only dolphins.) While the basis for this is uncertain, it is possibly related to Kahnemann's idea of certain intuitive thoughts being more accessible and coming to mind more easily than others [49]. 
Based on student comments and feedback, a third outcome of The Walk-Around Exercise is that students are more likely to treat all information 3-dimensionally regardless of its nature (e.g., including words and numbers). They tend to view all information as merely part of some larger pattern. This would appear to be consistent with the tenet that mental imagery is not merely symbolic, but instead is, at least in part, represented in a depictive format [50]. This tendency to look for larger patterns is supported by introducing the students to concepts surrounding fractal dimensions including the work of Mandelbrot [51] and the fractal flame-based animations of Scott Draves (e.g., http://www.electricsheep.org) [52].

\subsection{Ritual/Cyclical}

5.6.1. Personal Space. One of the textbook chapters and the classroom course presentations concern the usefulness of preparing personal space at home and at work in support of contemplative practices, openness, and creativity. The idea is not novel as it is used extensively at a population level in corporations such as Google, Facebook, SKYPE, Pixar, and Coaxis. However, at the personal level and within the controlable space, each scientist can determine what would support the most open and creative local environment. Students are challenged to evaluate the space they subject themselves to on a daily basis. That is their ritual. They are asked to consider the ideal personal space and potentially useful adjustments to their desk area and room decorations, as well as visual and auditory cues. For example, one question that can prompt surprise among academic scientists is whether their office decorations reflect more of where they have been in their career or where they are going? Creating personal space that can help to propel us toward career goals can be a simple, yet useful tool.

\section{Conclusions}

Within STEM education, the biomedical sciences are an ideal academic area for integration of contemplative practices into the curriculum. Because this curriculum supports the development of future MD and DVM clinicians, as well as advanced-degree researchers, exposure to contemplative tools can support a differently-focused, more holistic approach to health and well-being. What had begun as an uncertain curricular idea at Cornell has emerged as what appears to be a highly useful student experience based on student evaluations. When health science-oriented students have these tools available, they have more options for accessing information, perceptional awareness, and problem solving. Based on course evaluations, the students focus on a longer view of their emerging career opting to concentrate on their end career goal(s) rather than fretting over the minutia of the path and processes. Additionally, the increased self-awareness and self-regulation that students gain from working with the contemplative tools appear to be both empowering and translatable to their other coursework. The students move forward with additional problem-solving skills not often provided via STEM education. Precisely how that impacts their effectiveness as scientists across their careers remains to be determined.

\section{Conflict of Interests}

The author declares that there is no conflict of interests regarding the publication of this paper.

\section{Acknowledgments}

The author thanks the Center for Contemplative Mind in Society (Northampton, Massachusetts) for permission to reproduce their Tree of Contemplative Practices as Figure 1 as well as the Department of Microbiology and Immunology and the College of Veterinary Medicine at Cornell for the opportunity to introduce contemplative practices into the university's biomedical curriculum. The effort of Dr. Jerrie Gavalchin as coinstructor of the ANSC/BIOMS 4400 course is much appreciated as is the editorial assistance provided by Janice Dietert, Performance Plus Consulting.

\section{References}

[1] R. R. Dietert and J. Dietert, Science Sifting: Tools for Innovation in Science and Technology, World Scientific Publications, Singapore, 2013.

[2] The Center for Contemplative Mind in Society, The Tree of Contemplative Practices, Northampton, Mass, USA, 2014, http://www.contemplativemind.org/practices/tree.

[3] A. Zajonc, "Contemplative pedagogy: a quiet revolution in higher education," New Directions for Teaching and Learning, vol. 2013, no. 134, pp. 83-94, 2013.

[4] J. Simmer-Brown, Meditation and the Classroom: Contemplative Pedagogy for Religious Studies, SUNY Press, Albany, NY, USA, 2011.

[5] W. B. Britton, A. Brown, C. T. Kaplan et al., "Contemplative science: an insider prospectus," New Directions for Teaching and Learning, vol. 2013, no. 134, pp. 13-29, 2013.

[6] National Governor's Association Center for Best Practices, "Science, Technology, Engineering, \& Math (STEM) Education," http://www.nga.org/cms/render/live/stem.

[7] National Research Council, Successful K-12 STEM Education: Identifying Effective Approaches in Science, Technology, Engineering, and Mathematics, Committee on Highly Successful Science Programs for K-12 Science Education, Board on Science Education and Board on Testing and Assessment, Division of Behavioral and Social Sciences Education, The National Academies Press, Washington, DC, USA, 2011.

[8] Stem Education Coalition, "The Case for STEM Education as a National Priority: Good Jobs and American Competitiveness," 2013, http://www.stemedcoalition.org/wp-content/uploads/ 2013/10/Fact-Sheet-STEM-Education-Good-Jobs-and-American-Competitiveness-June-2013.pdf.

[9] R. R. Dietert, J. C. DeWitt, D. R. Germolec, and J. T. Zelikoff, "Breaking patterns of environmentally influenced disease for health risk reduction: immune perspectives," Environmental Health Perspectives, vol. 118, no. 8, pp. 1091-1099, 2010.

[10] R. R. Dietert, "Fractal immunology and immune patterning: potential tools for immune protection and optimization," Journal of Immunotoxicology, vol. 8, no. 2, pp. 101-110, 2011. 
[11] R. Dietert and J. Dietert, “The completed self: an immunological view of the human-microbiome superorganism and risk of chronic diseases," Entropy, vol. 14, no. 11, pp. 2036-2065, 2012.

[12] T. McCaffrey, "Innovation relies on the obscure: a key to overcoming the classic problem of functional fixedness," Psychological Science, vol. 23, no. 3, pp. 215-218, 2012.

[13] S. M. Ritter, M. Strick, M. W. Bos, R. B. van Baaren, and A. Dijksterhuis, "Good morning creativity: task reactivation during sleep enhances beneficial effect of sleep on creative performance," Journal of Sleep Research, vol. 21, no. 6, pp. 643647, 2012.

[14] R. Ness, Innovation Generation: How to Produce Creative and Useful Scientific Ideas, Oxford University Press, New York, NY, USA, 2012.

[15] R. Davidson, J. Dunne, J. S. Eccles et al., "Contemplative practices and mental training: prospects for American education," Child Development Perspectives, vol. 6, no. 2, pp. 146-153, 2012.

[16] D. R. Vago and D. A. Silbersweig, "Self-awareness, selfregulation, and self-transcendence (S-ART): a framework for understanding the neurobiological mechanisms of mindfulness," Frontiers in Human Neuroscience, vol. 6, article 296, 2012.

[17] R. W. Roeser and S. C. Peck, "An education in awareness: self, motivation, and self-regulated learning in contemplative perspective," Educational Psychologist, vol. 44, no. 2, pp. 119-136, 2009.

[18] R. Feynman, Surely You're Joking, Mr. Feynman, W.W. Norton, New York, NY, USA, 1985.

[19] J. H. Cullen, Barbara McClintock, Infobase Publishing, New York, NY, USA, 2003.

[20] E. F. Keller, A Feeling for the Organism: The Life and Work of Barbara McClintock, Macmillan, New York, NY, USA, 1983.

[21] A. Zajonc, "Love and knowledge: recovering the heart of learning through contemplation," Teachers College Record, vol. 108, no. 9, pp. 1742-1759, 2006.

[22] R. P. Nagendra, N. Maruthai, and B. M. Kutty, "Meditation and its regulatory role on sleep," Frontiers in Neurology, vol. 3, article $54,2012$.

[23] X. Ding, Y. Y. Tang, R. Tang, and M. R. Posner, "Improving creativity performance by short-term meditation," Behavioral and Brain Functions, vol. 10, article 9, 2014.

[24] C. Regehr, D. Glancy, A. Pitts, and V. R. Leblanc, "Interventions to reduce the consequences of stress in physicians: a review and meta-analysis," Journal of Nervous and Mental Disease, vol. 202, no. 5, pp. 353-359, 2014.

[25] J. P. Manikonda, S. Störk, S. Tögel et al., "Contemplative meditation reduces ambulatory blood pressure and stressinduced hypertension: A randomized pilot trial," Journal of Human Hypertension, vol. 22, no. 2, pp. 138-140, 2008.

[26] E. R. Kasala, L. N. Bodduluru, Y. Maneti, and R. Thipparaboina, "Effect of meditation on neurophysiological changes in stress mediated depression," Complementary Therapies in Clinical Practice, vol. 20, no. 1, pp. 74-80, 2014.

[27] M. Goyal, S. Singh, E. M. Sibinga et al., "Meditation programs for psychological stress and well-being: a systematic review and meta-analysis," Journal of the American Medical Association Internal Medicine, vol. 174, no. 3, pp. 357-368, 2014.

[28] A. P. Zanesco, B. G. King, K. A. Maclean, and C. D. Saron, "Executive control and felt concentrative engagement following intensive meditation training," Frontiers in Human Neuroscience, vol. 7, p. 566, 2013.
[29] W. B. Britton, J. R. Lindahl, B. R. Cahn, J. H. Davis, and R. E. Goldman, "Awakening is not a metaphor: the effects of Buddhist meditation practices on basic wakefulness," Annals of the New York Academy of Sciences, vol. 1307, pp. 64-81, 2014.

[30] J. R. Lindah, C. T. Kaplan, E. Winget, and W. B. Britton, "A phenomenology of meditation-induced light experiences: traditional buddhist and neurobiological perspectives," Frontiers in Psychology, vol. 4, article 973, 2014.

[31] Y. M. Rinpoche and E. Swanson, Joyful Wisdom: Embracing Change and Finding Freedom, Harmony Books, New York, NY, USA, 2009.

[32] D. Haynes, "Contemplative practice and the education of the whole person," ARTS: The Arts in Religious and Theological Studies, vol. 16, pp. 8-10, 2004.

[33] D. P. Barbezat and M. Bush, Contemplative Practices in Higher Education: Powerful Methods to Transform Teaching and Learning, John Wiley \& Sons, New York, NY, USA, 2013.

[34] V. K. Ranganathan, V. Siemionow, J. Z. Liu, V. Sahgal, and G. H. Yue, "From mental power to muscle power-gaining strength by using the mind," Neuropsychologia, vol. 42, no. 7, pp. 944956, 2004.

[35] M. D. Reiser, D. Büsch, and J. Munzert, "Strength gains by motor imagery with different ratios of physical to mental practice," Frontiers in Psychology, vol. 2, article 194, 2011.

[36] R. Brown, U. Kemp, and V. Macefield, "Increases in muscle sympathetic nerve activity, heart rate, respiration, and skin blood flow during passive viewing of exercise," Frontiers in Neuroscience, vol. 7, article 102, 2013.

[37] W. Whitecloud, The Magician's Way: What It Really Takes to Find Your Treasure, New World Library, Novato, Calif, USA, 2009.

[38] E. Bianchi, "Life review through meditative journaling," Journal of Religious Gerontology, vol. 8, no. 4, pp. 73-81, 1992.

[39] S. Brown and U. Volgsten, Eds., Music and Manipulation: On the Social Uses and Social Control of Music, Berghahn Books, New York, NY, USA, 2006.

[40] M. Beck, Finding Your Way in a Wild New World: Reclaim Your True Nature to Create the Life You Want, Simon and Schuster, New York, NY, USA, 2011.

[41] R. McManus, "Alda offers ways to improve science communication," NIH Record, vol. 43, no. 7, 2011, http://nihrecord.od .nih.gov/newsletters/2011/04_01_2011/story2.htm.

[42] M. Beck, Steering by Starlight: The Science and Magic of Finding Your Destiny, Rodale, Emmaus, Pa, USA, 2009.

[43] A. I. Miller, "Metaphor and scientific creativity," in Metaphor and Analogy in the Sciences, F. Hallyn, Ed., pp. 147-164, Springer, Amsterdam, The Netherlands, 2000.

[44] S. E. Schug, Speaking and sensing the self in authentic movement: the search for authenticity in a 21st century white urban middleclass community [Ph.D. thesis], 2010, paper no. 110.

[45] A. Bernard, W. Steinmuller, and U. Stricker, Ideokinesis: A Creative Approach to Human Movement and Body Alignment, North Atlantic Books, Berkeley, Calif, USA, 2012.

[46] M. Root-Bernstein and R. Root-Bernstein, "Dance your experiment," Psychology Today Online, 2014, http://www .psychologytoday.com/blog/imagine/200810/dance-your-experiment.

[47] J. Bohannon, "Why do scientists dance?" Science, vol. 330, no. 6005, p. 752, 2010.

[48] N. Myers, "Dance your PhD: embodied animations, body experiments, and the affective entanglements of life science research," Body \& Society, vol. 18, no. 1, pp. 151-189, 2012. 
[49] D. Kahneman, "A perspective on judgment and choice: mapping bounded rationality," American Psychologist, vol. 58, no. 9, pp. 697-720, 2003.

[50] K. J. S. Lewis, G. Borst, and S. M. Kosslyn, "Integrating visual mental images and visual percepts: new evidence for depictive representations," Psychological Research, vol. 75, no. 4, pp. 259271, 2011.

[51] B. B. Mandelbrot, The Fractal Geometry of Nature, Henry Holt \& Company, New York, NY, USA, 1982.

[52] S. Draves, "The electric sheep screen-saver: a case study in aesthetic evolution," in Applications of Evolutionary Computing, F. Rothlauf, J. Branke, S. Cagnoni et al., Eds., pp. 458-467, Springer, Berlin, Germany, 2005. 

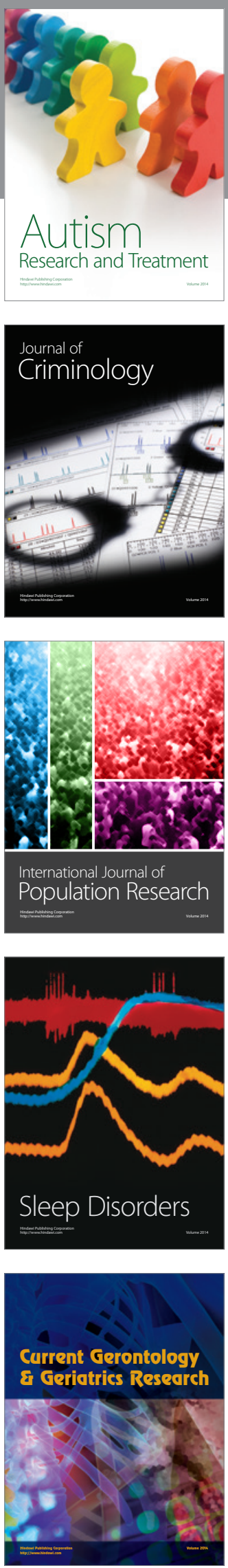
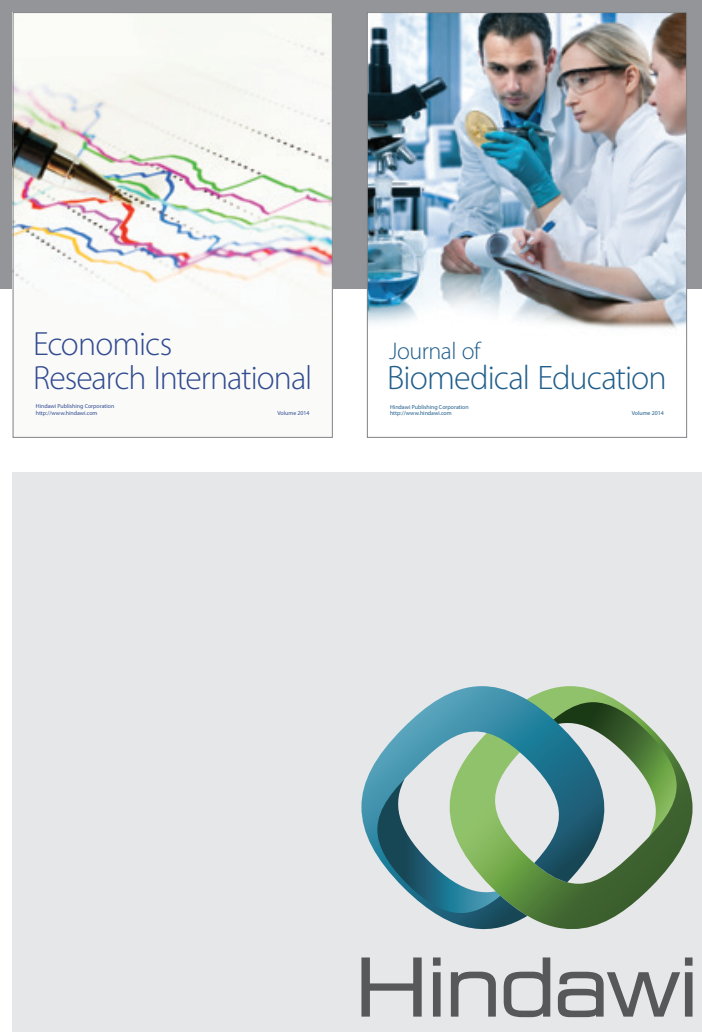

Submit your manuscripts at

http://www.hindawi.com
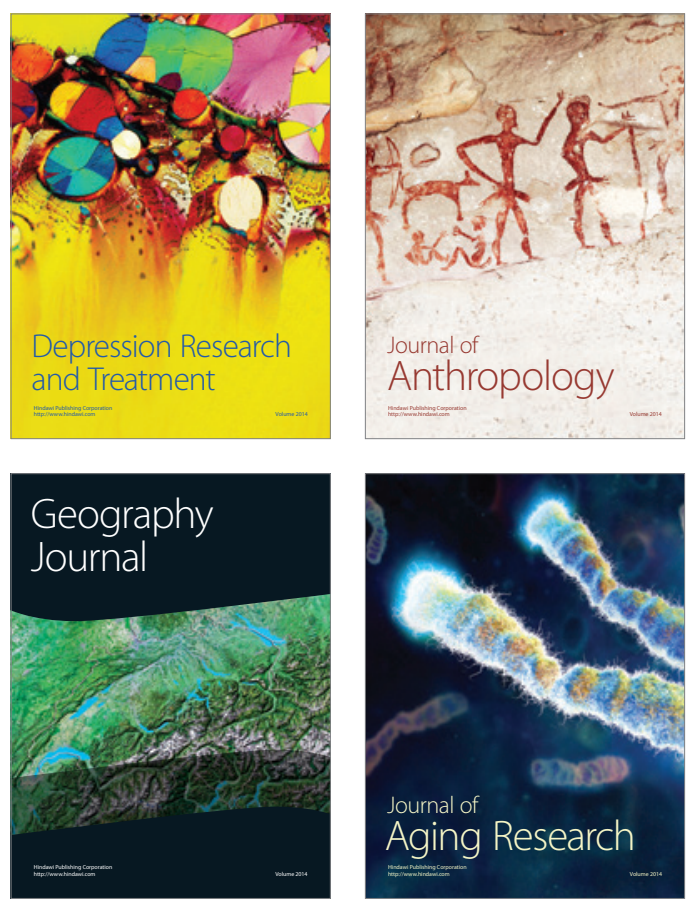
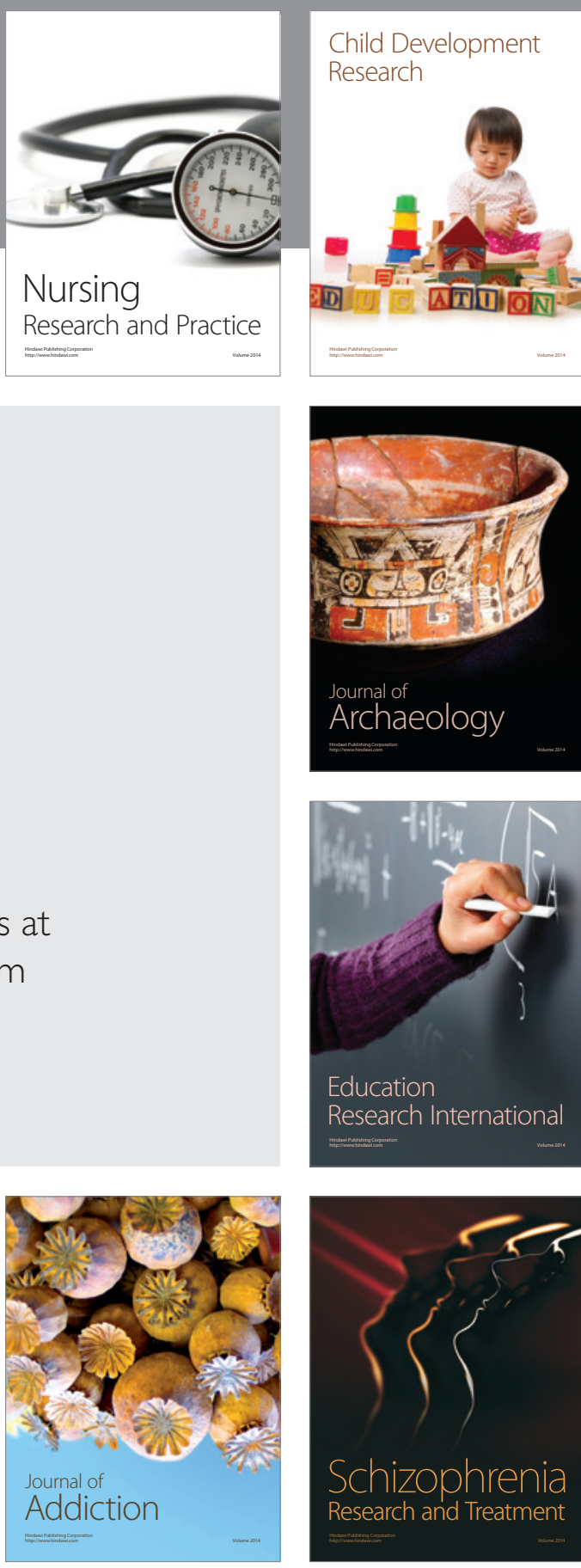

(D)
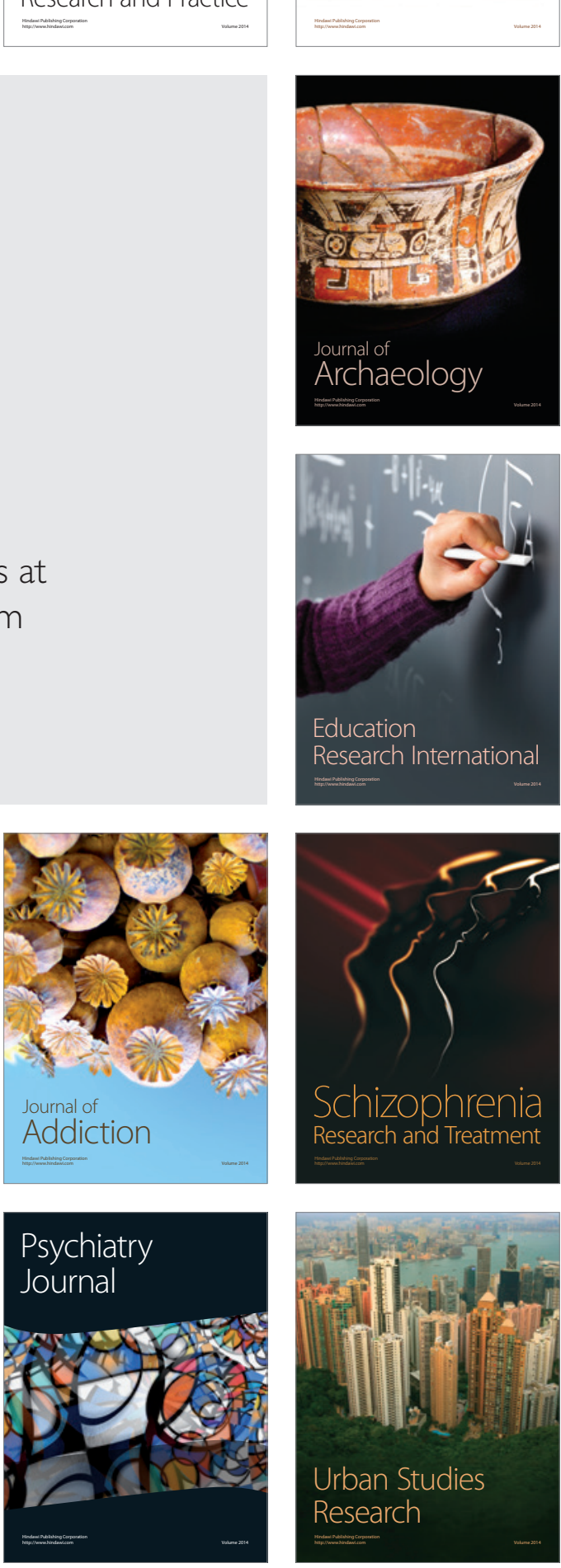